\title{
PROPHYLACTIC PROCAINE AMIDE IN MYOCARDIAL INFARCTION
}

\author{
BY \\ P. C. REYNELL \\ From the Department of Cardiology, Bradford A Group Hospitals \\ Received January 18, 1961
}

Of patients with myocardial infarction who survive long enough to be admitted to hospital, ten per cent die suddenly and often unexpectedly (Wood, 1956). Whereas deaths from overwhelming shock, congestive cardiac failure, or cardiac rupture are usually inevitable, due to the massive destruction of cardiac muscle, the sudden deaths may be more tragic in that they may occur in patients with apparently good cardiac reserve who might otherwise have made good functional recoveries. Most of them probably die of ventricular fibrillation which is the cause of sudden death after experimental coronary occlusion (Harris, 1950). In man the diagnosis is usually inferential as there are no diagnostic signs at autopsy, but ventricular fibrillation is found on the rare occasions when such patients die suddenly during cardiographic examination (Stroud and Feil, 1948).

Oral procaine amide may reverse abnormal ventricular rhythms (Kayden et al., 1951) and is said to be an effective prophylactic against abnormal rhythms during anaesthesia (Burstein, 1952). Wood (1956) writes "quinidine or pronestyl may be given by mouth as a prophylactic agent when the risk of ventricular fibrillation is great." A controlled trial of prophylactic oral procaine amide was therefore undertaken in patients admitted to hospital with myocardial infarction.

Methods. The patients constitute a consecutive personal series seen over a period of $2 \frac{1}{2}$ years. All had pain in the chest and cardiographs showing pathological Q waves and/or significant elevation of the S-T segment. Patients with silent infarcts or $\mathrm{T}$ wave changes only were rejected, and also those in whom infarction had occurred more than four days before admission to hospital. In order to limit the possible causes of death, severely shocked patients and those with congestive cardiac failure or serious complicating disease were excluded.

After the decision to accept him for the trial had been made, each patient was allocated by tossing a coin to treatment or control group. Two different dosage schedules were used consecutively (series 1 and 2) and each series of patients included concurrent untreated controls. Series 1 consisted of 44 patients and those who were treated were given procaine amide, $0.5 \mathrm{~g}$. four times a day, from the end of the first week after infarction until the end of the fourth week. Series 2 consisted of 62 patients and those who were treated were given procaine amide, $1.0 \mathrm{~g}$. four times a day for the first week after admission, and $0.5 \mathrm{~g}$. four times a day for a further week.

Twelve-lead electrocardiographs and white cell counts were done weekly in all patients and all were treated with anticoagulants unless there was evidence of recently active peptic ulceration or bleeding while on the drugs. Treated and untreated groups were reasonably comparable in respect of age and sex (Table I). 
TABLE I

Age and Sex Distribution of the Two Groups

\begin{tabular}{|c|c|c|c|c|c|c|}
\hline & & \multirow[t]{2}{*}{ Total } & \multicolumn{2}{|c|}{ Sex } & \multicolumn{2}{|c|}{ Age } \\
\hline & & & Men & Women & Over 60 & Under 60 \\
\hline $\begin{array}{l}\text { Patients given procaine amide } \\
\text { Controls }\end{array}$ & $\because$. & $\begin{array}{l}51 \\
55\end{array}$ & $\begin{array}{l}42 \\
39\end{array}$ & $\begin{array}{r}9 \\
16\end{array}$ & $\begin{array}{l}27 \\
30\end{array}$ & $\begin{array}{l}24 \\
25\end{array}$ \\
\hline
\end{tabular}

\section{COMPARISON OF RESULTS}

\section{Deaths}

The number of deaths was the same in treated and untreated groups (Table II). In series 1 there was one death in a treated patient and one in a control, and in series 2 there were four deaths among treated patients and four among controls. On clinical grounds the deaths could be subdivided into two groups.

1. Death from Delayed Shock (Cases 5, 7, 10), when hypotensive shock supervened after admission to the trial. Extension or recurrence of infarction seemed the likely explanation and two of the patients had severe retrosternal pain during the terminal episode.

2. Sudden Death (Cases 1, 2, 3, 4, 6, 8, 9), presumed due to ventricular fibrillation. There were four deaths in this category among the treated group and three among the controls.

TABLE II

Deaths in Treated and Control Groups

\begin{tabular}{|c|c|c|c|c|}
\hline Cause of death & & Delayed shock & Sudden death & Total \\
\hline $\begin{array}{l}\text { Patients on procaine amide } \\
\text { Controls } \ldots\end{array}$ & $\begin{array}{l}\cdots \\
\ldots\end{array}$ & $\begin{array}{l}1 \\
2\end{array}$ & $\begin{array}{l}4 \\
3\end{array}$ & $\begin{array}{l}5 \\
5\end{array}$ \\
\hline
\end{tabular}

A post-mortem examination was made in all the treated patients who died. In each case the findings were those of coronary occlusion with infarction without any major complicating lesion that might have contributed to death.

Brief notes on the fatal cases are given below.

Treated Patients. 1. Man, aged 55. Series 1. Bronchitis and mild left hemiparesis three days before admission. Admitted with chest pain, B.P. 110/70. Posterior infarction with heart block. Improved with reversion to sinus rhythm. Collapsed suddenly and died on 16th day.

2. Man, aged 67. Series 2. Severe retrosternal pain on admission. Prodromal attack lasting 30 minutes on previous day. B.P. 140/90. Antero-septal infarction. One week after admission collapsed suddenly and died within three minutes.

3. Man, aged 71. Series 2. Two years angina of effort. Severe retrosternal pain on day of admission. B.P. 110/85. Postero-lateral infarction. Made good progress until third day when he suddenly collapsed and died.

4. Man, aged 53. Series 2. Hypertension for 8 years. Three attacks of severe angina at rest during 24 hours before admission. B.P. 160/110. Posterior infarction. Recurrence of pain on afternoon after admission; developed dyspnœa and basal crepitations; and given digitalis. During next 48 hours dyspnœa improved and pulse rate fell from 110 to 85 a minute. Sudden collapse and death three days after admission.

5. Man, aged 54. Series 2. Angina at rest 15 days before admission. Awoke with severe retrosternal pain on day of admission. B.P. 120/80. Anterior infarction. Two or three short 
attacks of dyspnœa during 48 hours after admission. Anticoagulants stopped on fifth day owing to hæmaturia. Ten days after admission collapsed with recurrence of pain and blood pressure that was unrecordable but rose to $120 / 100$ after intravenous mephentermine: he remained clinically shocked until death three hours later.

Untreated Patients. 6. Man, aged 63. Series 1. Mild angina of effort for one year. Attacks of retrosternal pain at rest for ten days culminating in more severe attack on admission. Moderately shocked; B.P. 130/70. Posterior infarction with heart block. General condition remained poor with Cheyne-Stokes breathing at night. Sudden collapse and death 9 days after admission.

7. Man, aged 69. Series 2. Coronary thrombosis ten months previously with angina of effort since. Pale and sweating with pain on admission. B.P. 90/60. Anterior infarction. Nine hours after admission, recurrence of pain and blood pressure became unrecordable. No response to mephentermine. Died in one hour.

8. Man, aged 61. Series 2. Coronary thrombosis three months previously. Retrosternal pain on day of admission. B.P. 105/80. Suddenly collapsed and died 92 hours after admission.

9. Woman, aged 43. Series 2. Sudden onset of retrosternal pain in previously fit woman. B.P. 180/100. Anterior infarction. Twelve hours after onset of pain, collapsed suddenly and died within three minutes.

10. Woman, aged 71. Series 2. Angina of effort for eleven years. Onset with left-sided chest pain. B.P. 120/70. Some ectopic beats. Two days after admission, further attack of pain. Collapsed on following day; B.P. 50/?. No response to oxygen and mephentermine, and died one and a half hours later.

\section{Abnormal Rhythms}

In tabulating the incidence of abnormal rhythms (Table III), the results in series 1 and 2 have been combined. Only the arrhythmias recorded in the routine weekly cardiographs have been

TABLE III

AbNormal Rhythms in Treated and Control Groups

\begin{tabular}{|c|c|c|c|c|}
\hline & & $\begin{array}{c}\text { Minor } \\
\text { arrhythmia }\end{array}$ & $\begin{array}{c}\text { Major } \\
\text { arrhythmia }\end{array}$ & Total \\
\hline $\begin{array}{l}\text { Patients on procaine amide } \\
\text { Controls } \ldots\end{array}$ & $\begin{array}{l}\ldots \\
\ldots\end{array}$ & $\begin{array}{l}8 \\
5\end{array}$ & $\begin{array}{l}2 \\
7\end{array}$ & $\begin{array}{l}10 \\
12\end{array}$ \\
\hline
\end{tabular}

included. This naturally underestimates the true incidence, but it seemed the only possible completely objective basis for comparison between the two groups. Cardiographs recording less than three ectopic beats per record were classified as "minor abnormalities". The major abnormalities were all records showing multiple ectopic beats except for one from a control patient showing paroxysmal atrial tachycardia. Abnormal rhythms were recorded in ten of the treated patients and twelve of the controls. Minor abnormalities were a little commoner among the treated group and major abnormalities among the controls, but the difference is not impressive.

Side Effects. The only untoward side effects were gastro-intestinal. Vomiting, diarrhœa, or abdominal pain occurred in three patients on one gram of procaine amide q.i.d., but the symptoms subsided when the dose was halved. Alarming granulopenia was not seen.

\section{Discussion}

Although there has been no previously recorded trial of procaine amide, quinidine has been given prophylactically to patients with myocardial infarction with the object of preventing ventricular fibrillation. Boone and Pappas (1956) were impressed with the results, but Cutts and Rapoport (1952) found that deaths from ventricular fibrillation were not reduced. There has, however, 
been no scientifically acceptable trial of quinidine using simultaneous controls with random allocation of the drug.

The present trial indicates that oral procaine amide in the doses used did not protect against ventricular fibrillation in myocardial infarction. It is possible that it reduced the number of major arrhythmias and that larger or more frequent doses might have been beneficial, but one gram six-hourly approaches the limit of what is practical for routine prophylaxis if undesirable side effects are to be avoided. The risk of agranulocytosis can never be excluded (Inouye et al., $1951)$ and, at $£ 2$ per patient, the treatment is costly.

\section{SUMMARY}

A controlled trial of oral procaine amide given prophylactically to patients with myocardial infarction indicated that the drug did not reduce the mortality or the incidence of major abnormal rhythms.

I am grateful to Messrs. E. R. Squibb and Sons for a supply of pronestyl and to my registrars and house physicians for their loyal co-operation throughout the trial.

\section{REFERENCES}

Boone, J. A., and Pappas, A. (1956). Southern med. J., 49, 169.

Burstein, C. L. (1952). Anesthesiology, 13, 510.

Harris, A. S. (1950). Circulation, 1, 1318.

Inouye, M., Millar, J., and Townsend, J. (1951). J. Amer. med. Ass., 147, 652.

Kayden, H. J., Steele, J. M., Mark, L. C., and Brodie, B. B. (1951). Circulation, 4, 13.

Stroud, M. W., and Feil, H. S. (1948). Amer. Heart J., 35, 910.

Wood, P. (1956). Diseases of the Heart and Circulation. Eyre and Spottiswoode, London. 